\title{
Prognostic Significance of Inflammatory Biomarkers in Patients with Breast Cancer Skeletal Metastases
}

This article was published in the following Dove Press journal: Cancer Management and Research

\section{Yuan Wang (D) \\ Guilin Huang (D) \\ Zhigang Li}

Department of Gastrointestinal and Mammary Surgery, First Affiliated Hospital of Medical College of Shihezi University, Shihezi, Xinjiang Uygur Autonomous Region, 832000, People's Republic of China
Correspondence: Yuan Wang Department of Gastrointestinal and Mammary Surgery, First Affiliated Hospital of Medical College of Shihezi University, Xinjiang Uygur Autonomous Region, Shihezi 832000, People's Republic of China

Tel +86- I8199685586

Email363828464@qq.com
Purpose: Skeletal metastases are a common problem in breast cancer patients. Identifying new prognostic factors can improve survival estimations and guide healthcare professionals in therapeutic decision-making. Our study aimed to determine the prognostic value of inflammatory biomarkers such as neutrophil-to-lymphocyte ratio (NLR), lymphocyte-tomonocyte ratio (LMR), and C-reactive protein/albumin ratio (CAR) in patients with breast cancer skeletal metastases.

Patients and Methods: Clinical data from 212 patients with breast cancer skeletal metastases were retrospectively analyzed. The optimal cut-off values of each inflammatory biomarker were extracted from the receiver operating characteristic (ROC) curves. Patients were divided into high-value and low-value groups according to the cut-off values of NLR, LMR, and CAR. We investigated the relationship between inflammatory biomarkers and clinicopathological characteristics. The Kaplan-Meier method was used to measure progression-free survival (PFS) and overall survival (OS). The survival difference was compared by the univariate analysis. Cox multivariate regression analysis was performed to identify independent prognostic factors.

Results: The median age of the patients was 55 years, and the median follow-up was 45 months. $\mathrm{LMR}<3.43(\mathrm{P}<0.0001), \mathrm{NLR} \geq 2.48 \quad(\mathrm{P}<0.0001)$, and $\mathrm{CAR} \geq 0.34 \quad(\mathrm{P}=0.035)$ were found to be associated with worse PFS in the univariate analysis. Meanwhile, $\mathrm{LMR}<3.43$ $(\mathrm{P}<0.0001), \mathrm{NLR} \geq 2.48(\mathrm{P}<0.0001)$, and $\mathrm{CAR} \geq 0.34(\mathrm{P}=0.025)$ were linked to the poor $\mathrm{OS}$. The multivariate analysis revealed that $\mathrm{NLR} \geq 2.48$ (HR 2.044, $\mathrm{P}=0.007$ ) and $\mathrm{LMR}<3.43$ (HR 0.532, $\mathrm{P}=0.012$ ) were independent prognostic factors for $\mathrm{OS}$; $\mathrm{LMR}<3.43$ (HR 0.501 ; $\mathrm{P}=0.006$ ) and $\mathrm{NLR} \geq 2.48$ (HR 1.971, $\mathrm{P}=0.011$ ) were similarly prognosticating worse PFS. Radiotherapy to the affected bone and ER $(+)$ was favorable for the prognosis of breast cancer skeletal metastases. The number of involved sites of bone metastases $>3$ was adverse for PFS.

Conclusion: $\mathrm{LMR}<3.43$ and NLR $\geq 2.48$ were independently associated with worse prognosis of patients of breast cancer skeletal metastases.

Keywords: breast cancer skeletal metastases, inflammatory biomarkers, overall survival, progression-free survival, prognostic factor

\section{Introduction}

Breast cancer is the primary cause of death in feminine malignancies. ${ }^{1}$ Bone is the most common site of metastasis from breast cancer, and $75 \%$ of patients with latestage breast cancer will develop bone metastasis. ${ }^{2}$ Patients with bone metastasis generally experience skeletal-related events (SREs), such as spinal cord 
compression, serious ostalgia, as well as hypercalcemia and even pathological fracture, ${ }^{3}$ which result in reduced mobility and have a dramatic impact on the patient's quality of life inevitably.

Cancer patients present local and systemic modifications of the inflammatory response. ${ }^{4}$ The relationship between the components of the inflammatory response and the prognosis is a research topic that has gained great attention. ${ }^{5}$ Several inflammatory parameters have been extensively confirmed and employed by healthcare providers as prognostic indicators in various types of diseases in recent years. Duan et $\mathrm{al}^{6}$ summarized that preoperative elevated NLR was associated with poor prognosis in breast cancer. Mandaliya et $\mathrm{al}^{7}$ suggested that LMR was a prognostic biomarker in stage IV nonsmall cell lung cancer, and the prognostic role of CAR in esophageal cancer was demonstrated by Liu et al. ${ }^{8}$

Thio et $\mathrm{al}^{9}$ have investigated inflammatory biomarkers in patients with skeletal metastases from several malignancies and found that NLR can serve as an independent prognostic factor. However, on account of breast cancer patients with skeletal metastases, the prognostic significance of inflammatory biomarkers has not been entirely clear. As easy and cost-effective biomarkers, NLR, LMR, and CAR may reflect the level of inflammation in the body, with the trait of non-invasive, could be measured in peripheral blood. Therefore, our study aimed to determine whether NLR, LMR, and CAR are associated with prognosis in patients with breast cancer skeletal metastases, and to carry out a novel investigation into the utility of inflammatory these biomarkers as indicators in such patients.

\section{Patients and Methods}

\section{Patient Enrollment}

This study was based on the Helsinki Declaration and approved by the Ethics Committee of the First Affiliated Hospital of Medical College of Shihezi University. The written forms of informed consent for individual patients were not required since the study was retrospective, and all data analyzed is anonymous.

The analysis consists of a large cohort of consecutive breast cancer patients with skeletal metastases at the First Affiliated Hospital of Medical College of Shihezi University who had a measurement of NLR, LMR, and CAR before starting a new systemic therapy between January 2009 and June 2020. We enrolled patients with histological confirmation of breast cancer and they were diagnosed skeletal metastases by clinical manifestations, imaging examinations, or bone biopsies after the radical operation (mastectomy or breastconserving surgery, and axillary lymph node dissection or sentinel lymph node biopsy); they underwent systemic treatment subsequently. Data for differential blood counts were collected prior to a new systemic therapy (chemotherapy; endocrine therapy; targeted therapy; bisphosphonate treatment; surgery, or radiotherapy to the affected bone; analgesia, or other supportive treatments).

The exclusion criteria were as follows: 1) Patients with hematological, immune, inflammatory diseases, and inflammatory breast cancer; 2) Patients who used anti-inflammatory drugs or immunosuppressants before enrollment;3) Patients who refused systemic treatment according to the NCCN guidelines; ${ }^{10}$ 4) Patients with incomplete data for hematology or follow-up materials.

\section{Data Collection}

The data extracted from the medical record included: 1) Data for breast cancer: age, primary site, primary tumor size, histological pathology, histological grade, molecular subtype, type of breast cancer surgery, $\mathrm{T}$ stage, $\mathrm{N}$ stage, estrogen receptor (ER), progesterone receptor (PR), human epidermal growth factor receptor 2 (HER2) status, and Ki-67 label index. 2) Data for skeletal metastases: the first site of the affected bone, visceral metastasis during follow-up, the number of involved sites of bone metastases, and systemic therapy information were collected from the medical records. Differential blood counts were collected within one week before a new systemic therapy, and the counts of neutrophils, lymphocytes, monocytes, albumin, and C-reactive protein were extracted from blood counts and used to calculate the corresponding values of NLR, LMR, and CAR. Chemotherapy, targeted therapy, endocrine therapy, surgery and radiotherapy to the involved bone were administered in appropriate patients according to available clinical practice guidelines.

\section{Follow-Up}

Patients were followed-up regularly after the diagnosis of breast cancer skeletal metastases. The follow-up was scheduled three months, six months, twelve months after diagnosis, and then every year. The dates and causes of death were recorded if the patients were dead. The followup included assessing disease progression and confirming the patient's death or loss to follow-up.

In our study, we set June 2020 as the deadline for followup. OS represented the stretch from the time of the diagnosis 
until death for any reason. PFS is defined as the time elapsed between diagnosis and tumor progression.

\section{Statistical Analysis}

SPSS22.0 (SPSS Inc, Chicago, IL) was used to perform statistical analysis. Fisher's exact test or chi-squared test was adopted for categorical variables. The OS and PFS were evaluated by the Kaplan-Meier method, and the Log rank test was used to assess the survival differences between patients divided into two groups according to the optimal cutoff values of NLR, LMR, and CAR, which were obtained from time-dependent ROC curves. The Cox proportional hazard model was used for univariate and multivariate analyses to analyze the factors affecting the prognosis and to test for factors' independence. The hazard ratio (HR) and corresponding 95\% confidence intervals (CIs) were also calculated. Statistical tests were two-sided, and a $\mathrm{P}$ value $<0.05$ was considered to have statistical significance.

\section{Results}

\section{Patients Baseline Characteristics}

A total of 212 patients with breast cancer with skeletal metastases were included in this study (Figure 1), and the baseline characteristics were displayed in Table 1. The mean age of the population was 54.76 (median 55; range 25-85) years. Of the firstly affected bone, the thoracic spine was the most common location ( $\mathrm{n}=78)$, followed by the rib $(n=51)$, and the lumbar spine $(n=39)$. A little more than half of the patients $(52.4 \%)$ had multiple skeletal metastases $(\mathrm{n}=111)$. Concerning systemic therapy, patients all have received chemotherapy and surgical treatment of breast cancer, $66.5 \%$ have undergone radiotherapy to the primary site $(\mathrm{n}=141), 18.9 \%$ have received endocrine therapy $(\mathrm{n}=40), 54.2 \%$ have experienced targeted therapy $(\mathrm{n}=115)$, $75 \%$ patients have received bisphosphonate treatment $(\mathrm{n}=159)$, and those who have experienced radiotherapy to the affected bone account for $34.4 \%(n=73)$, undergone surgery to the affected bone take up $22.2 \%(n=47)$.

\section{The Cut-Off Values of Inflammatory Biomarkers}

Determined by the ROC curves, the optimal cut-off values of NLR, LMR and CAR were 2.48, 3.43, and 0.34, and the corresponding areas under the curves (AUCs) were 0.648, 0.625 , and 0.534 , respectively (Table 2, Figure 2). Patients were divided into low and high ratio groups according to cutoff values. $42.5 \%$ of the patients (90) had a low NLR $(<2.48)$, and $57.5 \%$ (122) had a high NLR ( $\geq 2.48) .50 .9 \%$ of patients

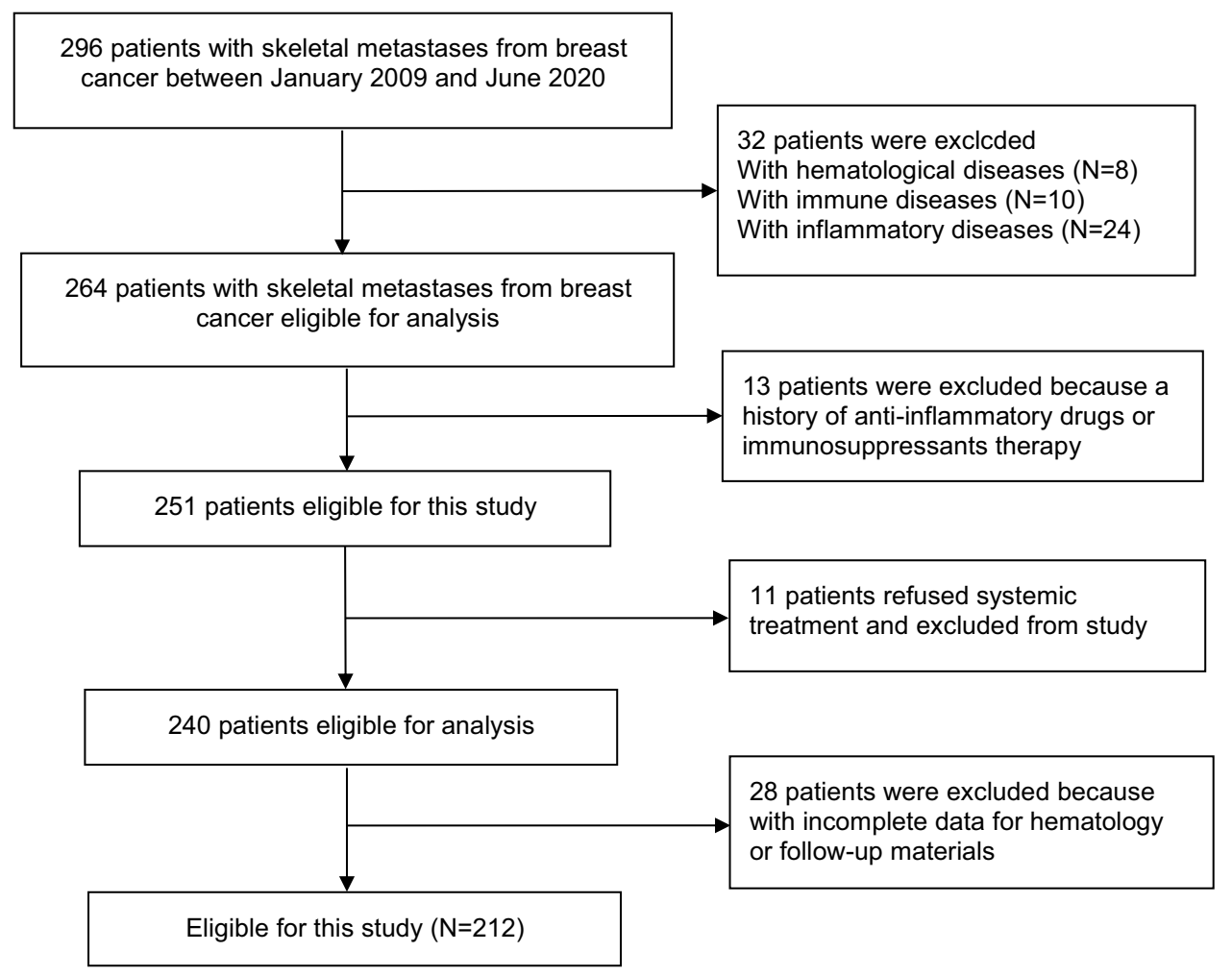

Figure I Study flow chart. 
Table I Clinicopathologic Characteristics of 212 Breast Cancer with Skeletal Metastases Patients

\begin{tabular}{|c|c|c|}
\hline Variables & Number & $\%$ \\
\hline \multicolumn{3}{|l|}{ Age (years) } \\
\hline$<55$ & 96 & 45.3 \\
\hline$\geq 55$ & 116 & 54.7 \\
\hline \multicolumn{3}{|l|}{ Pathology } \\
\hline Invasive ductal carcinoma & 195 & 92.0 \\
\hline Invasive lobular carcinoma & 13 & 6.1 \\
\hline Other & 4 & 1.89 \\
\hline \multicolumn{3}{|l|}{ Histological Grade } \\
\hline I-II & 76 & 35.8 \\
\hline III-IV & 136 & 64.2 \\
\hline \multicolumn{3}{|l|}{ T stage } \\
\hline TI & 18 & 8.5 \\
\hline $\mathrm{T} 2$ & 92 & 43.4 \\
\hline T3 & 42 & 19.8 \\
\hline T4 & 60 & 28.3 \\
\hline \multicolumn{3}{|l|}{$\mathrm{N}$ stage } \\
\hline No & 7 & 3.3 \\
\hline $\mathrm{NI}$ & 71 & 33.50 \\
\hline N2 & 97 & 45.7 \\
\hline N3 & 37 & 17.5 \\
\hline \multicolumn{3}{|l|}{ HER2 status } \\
\hline$(-)$ & 87 & 41.0 \\
\hline$(+)$ & 125 & 59.0 \\
\hline \multicolumn{3}{|l|}{ ER status } \\
\hline$(-)$ & 92 & 43.4 \\
\hline$(+)$ & 120 & 56.6 \\
\hline \multicolumn{3}{|l|}{ PR status } \\
\hline$(-)$ & 146 & 68.9 \\
\hline$(+)$ & 66 & 31.1 \\
\hline \multicolumn{3}{|l|}{ Ki-67 } \\
\hline$<14 \%$ & 71 & 33.5 \\
\hline$\geq 14 \%$ & $|4|$ & 66.5 \\
\hline \multicolumn{3}{|l|}{$\begin{array}{l}\text { The number of involved sites of visceral } \\
\text { metastases }\end{array}$} \\
\hline 0 & 106 & 50.0 \\
\hline 1 & 20 & 9.43 \\
\hline$>1$ & 86 & 40.6 \\
\hline \multicolumn{3}{|l|}{ The number of involved sites of bone metastases } \\
\hline 1 & 101 & 47.6 \\
\hline $2-3$ & 90 & 42.5 \\
\hline$>3$ & 21 & 9.9 \\
\hline \multicolumn{3}{|l|}{ Site of affected bone } \\
\hline Femur & 15 & 7.1 \\
\hline Rib & 51 & 24.1 \\
\hline
\end{tabular}

(Continued)
Table I (Continued).

\begin{tabular}{|c|c|c|}
\hline Variables & Number & $\%$ \\
\hline Lumbar spine & 39 & 18.4 \\
\hline Thoracic spine & 78 & 36.8 \\
\hline Humerus & 16 & 7.5 \\
\hline Other & 13 & 6.1 \\
\hline \multicolumn{3}{|l|}{ Type of breast cancer surgery } \\
\hline Breast-conserving surgery & 86 & 40.6 \\
\hline Radical mastectomy & 126 & 59.4 \\
\hline \multicolumn{3}{|l|}{ Number of chemotherapeutic line } \\
\hline First-line & 100 & 47.2 \\
\hline Second-line & 95 & 44.8 \\
\hline Third-line or more & 17 & 8.0 \\
\hline \multicolumn{3}{|l|}{ Primary site radiotherapy } \\
\hline No & 71 & 33.5 \\
\hline Yes & 141 & 66.5 \\
\hline \multicolumn{3}{|l|}{ Endocrine therapy } \\
\hline No & 172 & 81.1 \\
\hline Yes & 40 & 18.9 \\
\hline \multicolumn{3}{|l|}{ Targeted therapy } \\
\hline No & 97 & 45.8 \\
\hline Yes & 115 & 54.2 \\
\hline \multicolumn{3}{|l|}{ Bisphosphonate treatment } \\
\hline No & 53 & 25.0 \\
\hline Yes & 159 & 75.0 \\
\hline \multicolumn{3}{|l|}{ Surgery to the affected bone } \\
\hline No & 165 & 77.8 \\
\hline Yes & 47 & 22.2 \\
\hline \multicolumn{3}{|l|}{ Radiotherapy to the affected bone } \\
\hline No & 139 & 65.6 \\
\hline Yes & 73 & 34.4 \\
\hline \multicolumn{3}{|l|}{ NLR } \\
\hline$<2.48$ & 90 & 42.5 \\
\hline$\geq 2.48$ & 122 & 57.5 \\
\hline \multicolumn{3}{|l|}{ LMR } \\
\hline$<3.43$ & 108 & 50.9 \\
\hline$\geq 3.43$ & 104 & 49.1 \\
\hline \multicolumn{3}{|l|}{ CAR } \\
\hline$<0.34$ & 168 & 79.2 \\
\hline$\geq 0.34$ & 44 & 20.8 \\
\hline
\end{tabular}

Abbreviations: HER2, human epidermal growth factor receptor 2; NLR, neutrophil-to-lymphocyte ratio; LMR, lymphocyte-to-monocyte ratio; CAR, C-reactive protein/albumin ratio.

(108) were classified as low LMR (<3.43) and 49.1\% (104) as high LMR ( $\geq 3.43) .79 .2 \%$ of patients (168) were categorized as low CAR $(<0.34)$ and $20.8 \%$ (44) as high CAR $(\geq 0.34)$. 
Table 2 Receiver Operating Characteristics (ROC) Analyses of NLR, LMR, and CAR in Patients with Breast Cancer Skeletal Metastases

\begin{tabular}{|l|l|l|l|l|}
\hline Variables & Cut-Off Value & AUC (95\% CI) & Sensitivity & Specificity \\
\hline NLR & 2.48 & $0.648(0.573-0.722)$ & 0.738 & 0.523 \\
LMR & 3.43 & $0.625(0.549-0.701)$ & 0.591 & 0.675 \\
CAR & 0.34 & $0.534(0.452-0.616)$ & 0.300 & 0.848 \\
\hline
\end{tabular}

Abbreviations: NLR, neutrophil-to-lymphocyte ratio; LMR, lymphocyte-to-monocyte ratio; CAR, C-reactive protein/albumin ratio.

\section{Associations Between Inflammatory Biomarkers and Clinicopathological Characteristics}

Our analysis revealed that NLR was significantly associated with the $\mathrm{N}$ stage $(\mathrm{P}=0.018)$, and LMR was linked to the T stage $(\mathrm{P}=0.002)$ and $\mathrm{N}$ stage $(\mathrm{P}=0.045)$; However, there was no apparent association between $\mathrm{CAR}$ and the clinicopathological characteristics (Table 3).

\section{Survival}

The median duration of follow-up was 45.0 months (range 2.0 to 88.0 ). During follow-up, 72 patients (34.0\%) experienced the progression of the disease, and 80 patients (37.7\%) died. The Kaplan-Meier analyses of PFS and OS according to the cut-off values of NLR, LMR, and CAR were shown in Figure 3.

The rate of progression-free survival in patients with breast cancer skeletal metastases was $66 \%$, with a mean PFS of 28.82 (range 2-88) months. The PFS was worse in the group of NLR $\geq 2.48$ than NLR $<2.48$ (estimated 3-year PFS: $50.5 \%$ vs. $73.8 \%, \mathrm{P}<0.0001$ ), in the group of $\mathrm{LMR}<3.43$ than $\mathrm{LMR} \geq 3.43$ (estimated 3-year PFS: $45.6 \%$ vs. $75.6 \%, \mathrm{P}<0.0001)$ as well as in the group of $\mathrm{CAR} \geq 0.34$ than $\mathrm{CAR}<0.34$ (estimated 3-year PFS: $46.3 \%$ vs. $64.6 \%, \mathrm{P}=0.031)$.

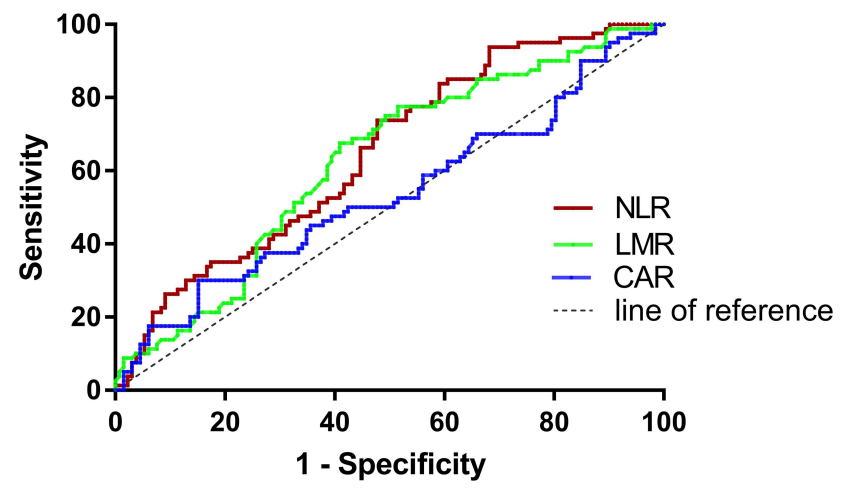

Figure 2 The receiver operating characteristic (ROC) curves of NLR, LMR and CAR.
A total of 80 patients $(37.7 \%)$ died during the followup period (mean 31.95 months; range 2-88 months), either directly related to breast cancer skeletal metastases or systemic therapy complications. The OS was significantly lower in the group of $\mathrm{NLR} \geq 2.48$ (estimated 3-year OS: $51.2 \%$ vs. $76.7 \%, \mathrm{P}<0.0001$ ), the group of $\mathrm{LMR}<3.43$ (estimated 3-year OS: $47.8 \%$ vs. $80.3 \%, \mathrm{P}<0.0001$ ), and the group of $\mathrm{CAR} \geq 0.34$ (estimated 3-year OS: $48.9 \%$ vs. $67.7 \%, \mathrm{P}=0.022$ ).

\section{Univariate and Multivariate Analyses of Prognostic Factors for PFS}

In univariate analysis, histological grade $(\mathrm{P}=0.016), \mathrm{ER}$ status $(\mathrm{P}=0.027)$, the number of involved sites of bone metastases $(\mathrm{P}=0.003)$, radiotherapy to the affected bone $(\mathrm{P}=0.009)$, NLR $(\mathrm{P}<0.0001)$, LMR $(\mathrm{P}<0.0001)$, and CAR $(\mathrm{P}=0.035)$ were significantly linked with PFS. All potential prognostic factors extracted from the univariate analysis were submitted for Cox proportional hazards analysis. Multivariate analysis indicated that patients with the number of involved sites of bone metastases $>3$ (HR 2.047; $\mathrm{P}=0.049$ ) and $\mathrm{NLR} \geq 2.48$ (HR 1.971; $\mathrm{P}=0.011$ ) were linked to worse PFS. The risk of progression was relatively decreased in patients who have received radiotherapy to the affected bone (HR 0.458; $\mathrm{P}=0.005$ ). Patients with ER $(+)$ had longer PFS (HR 0.601; $\mathrm{P}=0.026$ ), and a similar association was observed for $\mathrm{LMR} \geq 3.43$ (HR 0.501; $\mathrm{P}=0.006$ ) (Table 4).

\section{Univariate and Multivariate Analyses of Prognostic Factors for OS}

Univariate analysis revealed a significant impact of histological grade $(\mathrm{P}=0.020)$, ER status $(\mathrm{P}=0.031)$, the number of involved sites of bone metastases $>3(\mathrm{P}=0.005)$, radiotherapy to the affected bone ( $\mathrm{P}=0.009)$, NLR $(\mathrm{P}<0.0001)$, LMR $(\mathrm{P}<0.0001)$, and CAR $(\mathrm{P}=0.025)$ on OS. All potential prognostic factors were submitted for multivariate analysis. The results exhibited that the ER status, 
Table 3 Associations Between Inflammatory Biomarkers and Clinicopathological Characteristics

\begin{tabular}{|c|c|c|c|c|c|c|c|c|c|}
\hline \multirow[t]{2}{*}{ Variables } & \multicolumn{3}{|l|}{ NLR } & \multicolumn{3}{|l|}{ LMR } & \multicolumn{3}{|l|}{ CAR } \\
\hline & Low & High & $P$ value & Low & High & P value & Low & High & $P$ value \\
\hline \multicolumn{10}{|l|}{ Age (years) } \\
\hline$<55$ & 36 & 60 & & 51 & 45 & & 62 & 34 & \\
\hline$\geq 55$ & 54 & 62 & 0.184 & 57 & 59 & 0.563 & 84 & 32 & 0.220 \\
\hline \multicolumn{10}{|l|}{ Primary site } \\
\hline Upper inner & 11 & 11 & & II & 11 & & 18 & 4 & \\
\hline Lower inner & 19 & 15 & & 14 & 20 & & 27 & 7 & \\
\hline Upper outer & 35 & 48 & & 40 & 43 & & 57 & 26 & \\
\hline Lower outer & 14 & 24 & & 22 & 16 & & 22 & 16 & \\
\hline Other sites & 11 & 24 & 0.262 & 21 & 14 & 0.487 & 22 & 13 & 0.184 \\
\hline \multicolumn{10}{|l|}{ Tumor size } \\
\hline$<2 \mathrm{~cm}$ & 28 & 39 & & 29 & 38 & & 46 & 21 & \\
\hline$\geq 2 \mathrm{~cm},<5 \mathrm{~cm}$ & 40 & 42 & & 44 & 38 & & 57 & 25 & \\
\hline$>5 \mathrm{~cm}$ & 22 & 41 & 0.244 & 35 & 28 & 0.309 & 43 & 20 & 0.986 \\
\hline \multicolumn{10}{|l|}{ Histological type } \\
\hline Ductal & 84 & 111 & & 96 & 99 & & 136 & 59 & \\
\hline Lobular & 5 & 8 & & 9 & 4 & & 7 & 6 & \\
\hline Other & I & 3 & 0.735 & 3 & I & 0.235 & 3 & 1 & 0.470 \\
\hline \multicolumn{10}{|l|}{ Histological grade } \\
\hline I-II & 35 & 41 & & 35 & 41 & & 54 & 22 & \\
\hline III-IV & 55 & 81 & 0.428 & 73 & 63 & 0.287 & 92 & 44 & 0.608 \\
\hline \multicolumn{10}{|l|}{ T stage } \\
\hline TI & 7 & 11 & & 8 & 10 & & 14 & 4 & \\
\hline T2 & 44 & 48 & & 58 & 34 & & 64 & 28 & \\
\hline T3 & 14 & 28 & & 23 & 19 & & 25 & 17 & \\
\hline $\mathrm{T} 4$ & 25 & 35 & 0.453 & 19 & 41 & 0.002 & 43 & 17 & 0.455 \\
\hline \multicolumn{10}{|l|}{$\mathrm{N}$ stage } \\
\hline No & 6 & 1 & & 2 & 5 & & 4 & 3 & \\
\hline NI & 22 & 49 & & 45 & 26 & & 46 & 25 & \\
\hline N2 & 44 & 53 & & 42 & 55 & & 65 & 32 & \\
\hline N3 & 18 & 19 & 0.018 & 19 & 18 & 0.045 & 31 & 6 & 0.172 \\
\hline \multicolumn{10}{|l|}{ Molecular subtype } \\
\hline Luminal B HER2- & 19 & 30 & & 28 & 21 & & 34 & 15 & \\
\hline Luminal B HER2+ & 35 & 36 & & 33 & 38 & & 58 & 13 & \\
\hline HER2 enriched & 17 & 37 & & 29 & 25 & & 44 & 10 & \\
\hline Triple negative & 19 & 19 & 0.159 & 18 & 20 & 0.642 & 32 & 6 & 0.274 \\
\hline \multicolumn{10}{|l|}{ ER status } \\
\hline$(-)$ & 54 & 66 & & 61 & 59 & & 92 & 28 & \\
\hline$(+)$ & 36 & 56 & 0.391 & 47 & 45 & 0.971 & 76 & 16 & 0.290 \\
\hline \multicolumn{10}{|l|}{ PR status } \\
\hline$(-)$ & 56 & 90 & & 78 & 68 & & 115 & 31 & \\
\hline$(+)$ & 34 & 32 & 0.073 & 30 & 36 & 0.282 & 53 & 13 & 0.798 \\
\hline \multicolumn{10}{|l|}{ HER2 status } \\
\hline$(-)$ & 38 & 49 & & 46 & 41 & & 66 & 21 & \\
\hline$(+)$ & 52 & 73 & 0.763 & 62 & 63 & 0.639 & 102 & 23 & 0.311 \\
\hline
\end{tabular}

(Continued) 
Table 3 (Continued).

\begin{tabular}{|c|c|c|c|c|c|c|c|c|c|}
\hline \multirow[t]{2}{*}{ Variables } & \multicolumn{3}{|l|}{ NLR } & \multicolumn{3}{|l|}{ LMR } & \multicolumn{3}{|l|}{ CAR } \\
\hline & Low & High & $P$ value & Low & High & $P$ value & Low & High & $P$ value \\
\hline \multicolumn{10}{|l|}{ Ki-67 } \\
\hline$<14 \%$ & 32 & 39 & & 37 & 34 & & 51 & 20 & \\
\hline$\geq 14 \%$ & 58 & 83 & 0.584 & 71 & 70 & 0.809 & 95 & 46 & 0.509 \\
\hline \multicolumn{10}{|c|}{$\begin{array}{l}\text { The number of involved sites } \\
\text { of visceral metastases }\end{array}$} \\
\hline 0 & 47 & 59 & & 54 & 52 & & 80 & 26 & \\
\hline 1 & 7 & 13 & & 12 & 8 & & 16 & 4 & \\
\hline$>1$ & 36 & 50 & 0.733 & 42 & 44 & 0.793 & 72 & 14 & 0.161 \\
\hline \multicolumn{10}{|c|}{$\begin{array}{l}\text { The number of involved sites } \\
\text { of bone metastases }\end{array}$} \\
\hline 1 & 45 & 56 & & 49 & 52 & & 84 & 17 & \\
\hline $2-3$ & 38 & 52 & & 44 & 46 & & 67 & 23 & \\
\hline$>3$ & 7 & 14 & 0.638 & 15 & 6 & 0.141 & 17 & 4 & 0.326 \\
\hline
\end{tabular}

Note: Bold text, $\mathrm{P}$ value $<0.05$.

Abbreviations: OS, overall survival; HER2, human epidermal growth factor receptor 2; HR, hazard ratio; Cl, confidence interval; T, tumor; $\mathrm{N}$, lymph node involvement; NLR, neutrophil-to-lymphocyte ratio; LMR, lymphocyte-to-monocyte ratio; CAR, C-reactive protein/albumin ratio.

radiotherapy to the affected bone, NLR, and LMR were all essentially associated with OS. (ER+: HR 0.599, $\mathrm{P}=0.025$; undergone the radiotherapy to the affected bone: HR 0.452, $\quad \mathrm{P}=0.005 ; \quad \mathrm{NLR} \geq 2.48$ : $\mathrm{HR}$ 2.044, $\mathrm{P}=0.007$; $\mathrm{LMR} \geq 3.43$ : HR 0.532, $\mathrm{P}=0.012$ ) (Table 5).

\section{Discussion}

Skeleton is the most common metastatic site for breast cancer, and skeleton metastases seriously reduced life quality and expectancy following diagnosis. ${ }^{11,12}$ The highly heterogeneous in clinicopathological characteristics poses a considerable challenge in the systemic therapy of breast cancer skeletal metastases. Prolonging survival and preventing progression remain complicated issues. It is increasingly recognized that the systematic inflammatory response plays an essential role in the survival of malignancies. ${ }^{13}$ The prognostic value of several inflammatory parameters such as NLR, LMR and CAR has been reported to be associated with the outcome of various types of disease. ${ }^{14-17}$ However, there are no published studies regarding the prognostic significance of inflammatory biomarkers in breast cancer skeletal metastases. So our study aimed to identify possible prognostic factors for OS and PFS of breast cancer skeletal metastases patients through the combination of univariate and multivariate analyses with NLR, LMR, and CAR, to conduct a novel investigation into the utility of these inflammatory biomarkers as indicators in such patients.

Our research revealed that for patients with breast cancer skeletal metastases, $\mathrm{LMR}<3.43$ and $\mathrm{NLR} \geq 2.48$ were independently associated with PFS and OS. LMR and NLR are composite inflammatory biomarkers based on peripheral blood cells. LMR is calculated according to the formula: lymphocyte/monocyte; NLR means the ratio of neutrophil/lymphocyte. Therefore, a reasonable explanation for the underlying mechanism tended to be that lower LMR represents a lower count of lymphocytes, as well as a larger count of monocytes. An increase in NLR means growth in neutrophils, a reduction in lymphocytes, or both.

Lymphocytes are the main component involved in tumor immune response, which inhibits the proliferation of tumor cells through lymphocyte-mediated cytotoxicity and cytokines released. ${ }^{18,19}$ The lack of lymphocytes will lead to a decrease in CD4+ helper lymphocytes and an increase in CD8+ inhibitory cells to deteriorate the anti-tumor ability. ${ }^{20,21}$ Monocytes are considered pro-tumor cells as they promote the dissemination and progression of neoplasms. ${ }^{22}$ Tumor- $^{22}$ associated macrophage is relevant to the aggregation and differentiation of excessive monocytes in the 
A

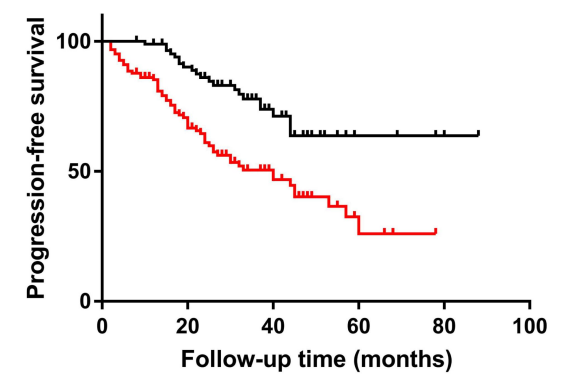

C

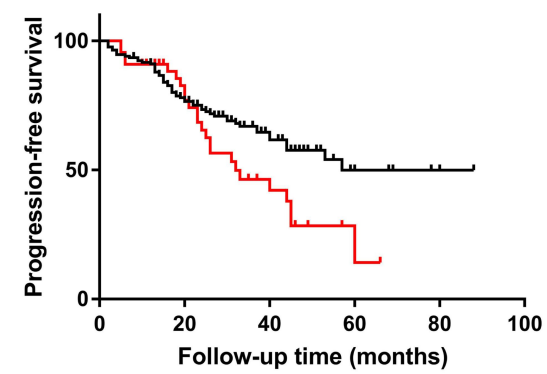

E

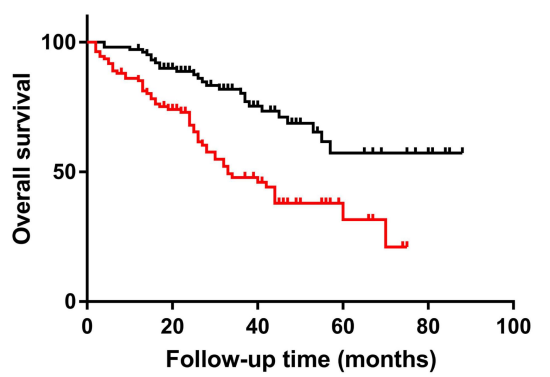

B
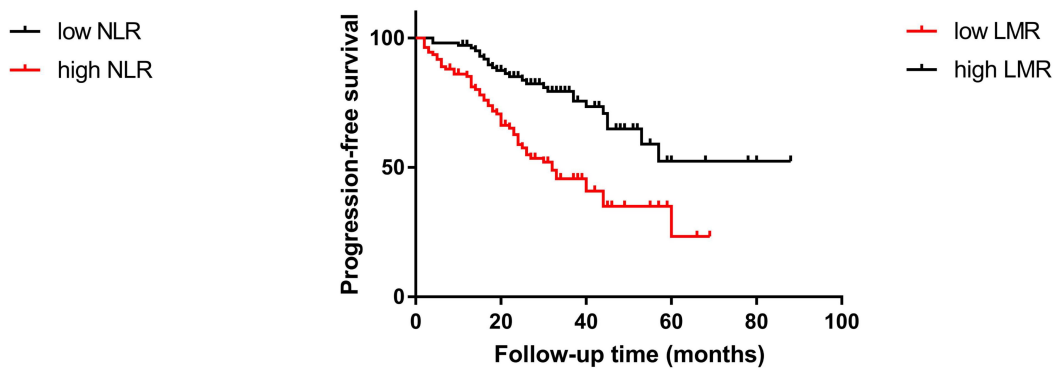

D

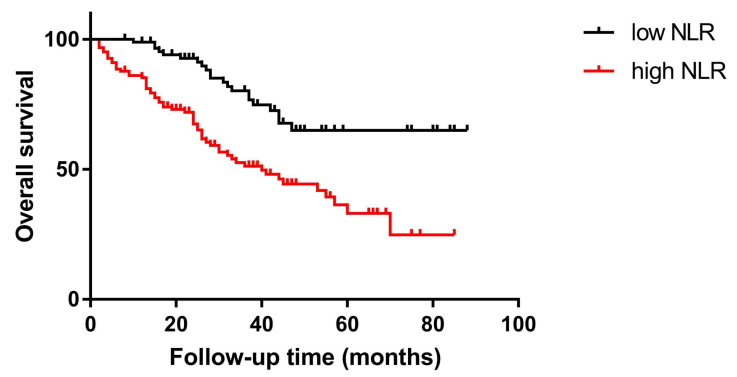

$\mathbf{F}$

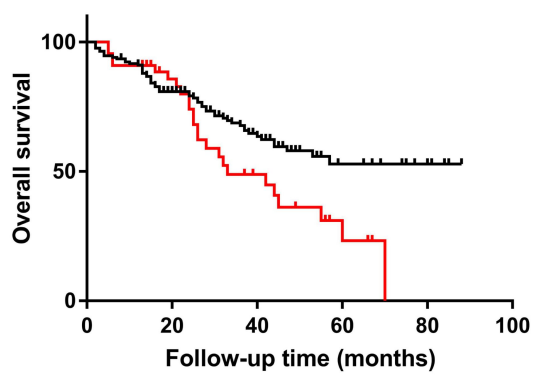

- IOW CAR

- high CAR

Figure 3 The Kaplan-Meier curves of PFS for (A) NLR, (B) LMR, (C) CAR, and the Kaplan-Meier curves of OS for (D) NLR, (E) LMR, (F) CAR.

tumor stroma, which not only advances tumor invasion but also lessens the aggressive ability of anti-tumor immune cells. ${ }^{23}$ Therefore, elevated monocytes in peripheral blood reflect the hard tumor burden of the body, and even the state of immunosuppression. ${ }^{24}$ Neutrophils support the proliferation, invasion, angiogenesis of tumor cells, and restrain the secretion of cytokines, which can exert direct or indirect killing effects. ${ }^{25}$ Current studies have proved that the neutrophils destroy tumors nonspecifically by generating reactive oxygen species, and the process is similar to the bactericidal mechanism. ${ }^{26,27}$ Whether neutrophils prevent the immune response of protection or promote the process of malignant skeletal metastases. ${ }^{28}$ Elevated NLR and reduced LMR may be related to inadequate immunocompetence in breast cancer patients with skeletal metastases. These theoretical foundations of inflammation may support the application of inflammatory symbols as prognostic indicators of bone metastases from breast cancer.

The main objectives of comprehensive treatment for breast cancer with bone metastasis are: 1) To relieve pain, rebuild function, and improve quality of life; 2) To treat and prevent SREs; 3) To control tumor progression 
Table 4 Associations Between Clinicopathologic Characteristics and PFS in Breast Cancer Skeletal Metastases Patients

\begin{tabular}{|c|c|c|c|c|c|c|}
\hline \multirow[t]{2}{*}{ Variables } & \multirow{2}{*}{$\begin{array}{l}\text { Number of } \\
\text { Patients }\end{array}$} & \multirow{2}{*}{$\begin{array}{l}\text { Number of } \\
\text { Events }\end{array}$} & \multicolumn{2}{|c|}{ Univariate Analysis } & \multicolumn{2}{|c|}{ Multivariate Analysis } \\
\hline & & & HR (95\% Cl) & $P$ value & HR (95\% Cl) & $P$ value \\
\hline \multicolumn{7}{|l|}{ Age (years) } \\
\hline$<55$ & 96 & 30 & 1 & & I & \\
\hline$\geq 55$ & 116 & 50 & $1.344(0.853-2.117)$ & 0.202 & 1 & I \\
\hline \multicolumn{7}{|l|}{ Histological grade } \\
\hline I-II & 76 & 19 & I & & I & \\
\hline III-IV & 136 & 61 & $1.883(1.125-3.153)$ & 0.016 & I.328(0.738-2.389) & 0.344 \\
\hline \multicolumn{7}{|l|}{ ER status } \\
\hline$(-)$ & 92 & 44 & I & & 1 & \\
\hline$(+)$ & 120 & 36 & $0.609(0.392-0.946)$ & 0.027 & $0.60 I(0.384-0.94 I)$ & 0.026 \\
\hline \multicolumn{7}{|l|}{ PR status } \\
\hline$(-)$ & 146 & 59 & 1 & & l & \\
\hline$(+)$ & 66 & 21 & $0.766(0.465-1.261)$ & 0.295 & l & I \\
\hline \multicolumn{7}{|l|}{ HER2 status } \\
\hline$(-)$ & 146 & 59 & 1 & & 1 & \\
\hline$(+)$ & 66 & 21 & $0.98 I(0.626-1.535)$ & 0.931 & I & I \\
\hline \multicolumn{7}{|l|}{$\mathrm{Ki}-67$} \\
\hline$<14 \%$ & 71 & 32 & I & & 1 & \\
\hline$\geq 14 \%$ & $|4|$ & 48 & $0.865(0.552-1.356)$ & 0.527 & I & I \\
\hline \multicolumn{7}{|c|}{$\begin{array}{l}\text { The number of involved sites of } \\
\text { visceral metastases }\end{array}$} \\
\hline 0 & 106 & 39 & 1 & & 1 & \\
\hline I & 20 & 12 & $1.748(0.915-3.342)$ & 0.091 & I & \\
\hline$>1$ & 86 & 29 & $0.818(0.503-1.330)$ & 0.418 & I & I \\
\hline \multicolumn{7}{|c|}{$\begin{array}{l}\text { The number of involved sites of bone } \\
\text { metastases }\end{array}$} \\
\hline 1 & 101 & 30 & 1 & & I & \\
\hline $2-3$ & 90 & 37 & $1.433(0.885-2.321)$ & 0.143 & $1.570(0.902-2.731)$ & 0.110 \\
\hline$>3$ & 21 & 13 & $2.659(1.383-5.110)$ & 0.003 & $2.047(1.003-4.179)$ & 0.049 \\
\hline \multicolumn{7}{|l|}{ Type of surgery } \\
\hline Breast-conserving surgery & 86 & 30 & I & & l & \\
\hline Radical mastectomy & 126 & 50 & $1.402(0.890-2.206)$ & 0.145 & l & I \\
\hline \multicolumn{7}{|c|}{ Radiotherapy to the primary site } \\
\hline No & 7II & 23 & I & & l & \\
\hline Yes & $|4|$ & 57 & $1.079(0.664-1.752)$ & 0.759 & I & I \\
\hline \multicolumn{7}{|l|}{ Endocrine therapy } \\
\hline No & 172 & 67 & I & & 1 & \\
\hline Yes & 40 & 13 & $0.712(0.393-1.291)$ & 0.264 & l & l \\
\hline \multicolumn{7}{|l|}{ Targeted therapy } \\
\hline No & 97 & 40 & I & & I & \\
\hline Yes & 115 & 40 & $0.674(0.434-1.046)$ & 0.079 & I & I \\
\hline \multicolumn{7}{|l|}{ Bisphosphonate treatment } \\
\hline No & 53 & 21 & 1 & & I & \\
\hline Yes & 159 & 59 & $0.896(0.544-1.475)$ & 0.666 & I & I \\
\hline
\end{tabular}

(Continued) 
Table 4 (Continued).

\begin{tabular}{|c|c|c|c|c|c|c|}
\hline \multirow[t]{2}{*}{ Variables } & \multirow{2}{*}{$\begin{array}{l}\text { Number of } \\
\text { Patients }\end{array}$} & \multirow{2}{*}{$\begin{array}{l}\text { Number of } \\
\text { Events }\end{array}$} & \multicolumn{2}{|l|}{ Univariate Analysis } & \multicolumn{2}{|c|}{ Multivariate Analysis } \\
\hline & & & HR (95\% Cl) & P value & HR (95\% Cl) & $P$ value \\
\hline \multicolumn{7}{|c|}{ Surgery to the affected bone } \\
\hline No & 165 & 63 & I & & l & \\
\hline Yes & 47 & 17 & $1.009(0.590-1.726)$ & 0.972 & I & I \\
\hline \multicolumn{7}{|c|}{ Radiotherapy to the affected bone } \\
\hline No & 139 & 62 & I & & 1 & \\
\hline Yes & 73 & 18 & $0.498(0.294-0.842)$ & 0.009 & $0.458(0.264-0.794)$ & 0.005 \\
\hline \multicolumn{7}{|l|}{ NLR } \\
\hline$<2.48$ & 90 & 21 & I & & 1 & \\
\hline$\geq 2.48$ & 122 & 59 & $2.667(1.619-4.394)$ & $<0.0001$ & $1.971(1.169-3.321)$ & 0.011 \\
\hline \multicolumn{7}{|l|}{ LMR } \\
\hline$<3.43$ & 120 & 36 & I & & 1 & \\
\hline$\geq 3.43$ & 92 & 44 & $0.376(0.235-0.601)$ & $<0.0001$ & $0.501(0.305-0.823)$ & 0.006 \\
\hline \multicolumn{7}{|l|}{ CAR } \\
\hline$<0.34$ & 168 & 56 & I & & 1 & \\
\hline$\geq 0.34$ & 44 & 24 & $1.675(1.038-2.702)$ & 0.035 & $1.297(0.79 \mid-2.127)$ & 0.302 \\
\hline
\end{tabular}

Note: Bold text: $P$ value $<0.05$.

Abbreviations: PFS, progression-free survival; HER2, human epidermal growth factor receptor 2; HR, hazard ratio; Cl, confidence interval; T, tumor; N, lymph node involvement; NLR, neutrophil-to-lymphocyte ratio; LMR, lymphocyte-to-monocyte ratio; CAR, C-reactive protein/albumin ratio.

and prolong patient survival. Systemic therapy is the dominant strategy, among which chemotherapy, endocrine therapy, and targeted therapy are fundamental, and bisphosphonates can prevent and deal with SREs. Reasonable local therapy controlled the symptoms of bone metastasis, surgery and radiotherapy are positive and effective methods to manipulate single bone metastasis. $^{29}$ Our result suggests that the number of involved sites of bone metastases $>3$ predicted worse PFS in patients. The multiple skeletal metastases posed a noticeable challenge in therapy, which is comparable to the result reported by Parkes et al. ${ }^{30}$ The radiotherapy to the affected bone can significantly reduce the progression rate and improve OS, which is necessary for breast cancer patients with skeletal metastases.

ER represents a primary transcription factor that promotes the formation of neoplasms in HR-positive breast cancer. $^{31,32}$ The biological effects of estrogen are mediated principally by ER-alpha, which acts as a ligandinducible transcription agent. ${ }^{33}$ Endocrine therapy is the first choice for patients with hormone-responsive breast cancer whose condition progresses slowly. Our findings explicated that ER $(+)$ as a potent favorable prognostic factor in the subset of patients with breast cancer bone metastasis, which is similar to the decision announced by Ren et al. ${ }^{34}$

To the best of our knowledge, this is the first study concerned the relationship between inflammatory biomarkers and the prognosis of breast cancer skeletal metastases. Still, there are limitations. 1) Patients included in the study only from one center, so international multi-center studies with larger sample sizes are required to verify our findings; 2) Our results are susceptible to some biases due to the retrospective nature. Therefore, prospective studies and extended follow-up duration are needed; 3) Patients who have not undergone the breast cancer surgical treatment were excluded so that the conclusion may not apply to them; 4) We adopted the ROC curves to determine the optimal critical values with both sensitivity and specificity, and the determination of the uniform cut-off values of inflammatory biomarkers may significantly advance the final consensus. Breast cancer skeletal metastasis is a complicated process, which involves plentiful factors. Prospective studies are required to further explore the potential mechanism, to prognosticate and screen the high-risk population with a worse prognosis and provide targeted intervention timely. 
Table 5 Associations Between Clinicopathologic Characteristics and OS in Breast Cancer Skeletal Metastases Patients

\begin{tabular}{|c|c|c|c|c|c|c|}
\hline \multirow[t]{2}{*}{ Variables } & \multirow{2}{*}{$\begin{array}{l}\text { Number of } \\
\text { Patients }\end{array}$} & \multirow{2}{*}{$\begin{array}{l}\text { Number of } \\
\text { Events }\end{array}$} & \multicolumn{2}{|c|}{ Univariate Analysis } & \multicolumn{2}{|c|}{ Multivariate Analysis } \\
\hline & & & HR (95\% Cl) & $P$ value & HR (95\% Cl) & $P$ value \\
\hline \multicolumn{7}{|l|}{ Age (years) } \\
\hline$<55$ & 96 & 30 & 1 & & I & \\
\hline$\geq 55$ & 116 & 50 & $1.306(0.829-2.058)$ & 0.250 & 1 & I \\
\hline \multicolumn{7}{|l|}{ Histological grade } \\
\hline I-II & 76 & 19 & I & & 1 & \\
\hline III-IV & 136 & 61 & $1.847(1.103-3.093)$ & 0.020 & I.3|4(0.73|-2.365) & 0.362 \\
\hline \multicolumn{7}{|l|}{ ER status } \\
\hline$(-)$ & 92 & 44 & 1 & & 1 & \\
\hline$(+)$ & 120 & 36 & $0.614(0.395-0.955)$ & 0.031 & $0.599(0.382-0.939)$ & 0.025 \\
\hline \multicolumn{7}{|l|}{ PR status } \\
\hline$(-)$ & 146 & 59 & I & & 1 & \\
\hline$(+)$ & 66 & 21 & $0.768(0.466-1.264)$ & 0.298 & l & l \\
\hline \multicolumn{7}{|l|}{ HER2 status } \\
\hline$(-)$ & 146 & 59 & 1 & & 1 & \\
\hline$(+)$ & 66 & 21 & $0.993(0.634-1.555)$ & 0.975 & I & I \\
\hline \multicolumn{7}{|l|}{$\mathrm{Ki}-67$} \\
\hline$<14 \%$ & 71 & 32 & I & & 1 & \\
\hline$\geq 14 \%$ & $|4|$ & 48 & $0.806(0.515-1.264)$ & 0.348 & I & I \\
\hline \multicolumn{7}{|c|}{$\begin{array}{l}\text { The number of involved sites of } \\
\text { visceral metastases }\end{array}$} \\
\hline 0 & 106 & 39 & I & & 1 & \\
\hline I & 20 & 12 & $1.489(0.779-2.845)$ & 0.229 & 1 & l \\
\hline$>1$ & 86 & 29 & $0.63 I(0.384-1.038)$ & 0.070 & I & I \\
\hline \multicolumn{7}{|c|}{$\begin{array}{l}\text { The number of involved sites of bone } \\
\text { metastases }\end{array}$} \\
\hline 1 & 101 & 30 & 1 & & 1 & \\
\hline $2-3$ & 90 & 37 & $1.427(0.88 \mathrm{I}-2.31 \mathrm{I})$ & 0.148 & $1.475(0.852-2.554)$ & 0.165 \\
\hline$>3$ & 21 & 13 & $2.553(1.331-4.900)$ & 0.005 & $1.925(0.946-3.918)$ & 0.071 \\
\hline \multicolumn{7}{|l|}{ Type of surgery } \\
\hline Breast-conserving surgery & 86 & 30 & I & & l & \\
\hline Radical mastectomy & 126 & 50 & $1.429(0.908-2.250)$ & 0.123 & l & I \\
\hline \multicolumn{7}{|c|}{ Radiotherapy to the primary site } \\
\hline No & 71 & 23 & I & & l & \\
\hline Yes & $|4|$ & 57 & $1.118(0.689-1.815)$ & 0.651 & l & I \\
\hline \multicolumn{7}{|l|}{ Endocrine therapy } \\
\hline No & 172 & 67 & I & & 1 & \\
\hline Yes & 40 & 13 & $0.710(0.392-1.287)$ & 0.259 & I & I \\
\hline \multicolumn{7}{|l|}{ Targeted therapy } \\
\hline No & 97 & 40 & I & & I & \\
\hline Yes & 115 & 40 & $0.682(0.440-1.059)$ & 0.089 & 1 & l \\
\hline \multicolumn{7}{|l|}{ Bisphosphonate treatment } \\
\hline No & 53 & 21 & I & & 1 & \\
\hline Yes & 159 & 59 & $0.903(0.549-1.487)$ & 0.688 & I & I \\
\hline
\end{tabular}

(Continued) 
Table 5 (Continued).

\begin{tabular}{|c|c|c|c|c|c|c|}
\hline \multirow[t]{2}{*}{ Variables } & \multirow{2}{*}{$\begin{array}{l}\text { Number of } \\
\text { Patients }\end{array}$} & \multirow{2}{*}{$\begin{array}{l}\text { Number of } \\
\text { Events }\end{array}$} & \multicolumn{2}{|c|}{ Univariate Analysis } & \multicolumn{2}{|c|}{ Multivariate Analysis } \\
\hline & & & HR (95\% Cl) & $P$ value & HR (95\% Cl) & $P$ value \\
\hline \multicolumn{7}{|c|}{ Surgery to the affected bone } \\
\hline No & 165 & 63 & 1 & & I & \\
\hline Yes & 47 & 17 & $1.031(0.603-1.763)$ & 0.912 & I & I \\
\hline \multicolumn{7}{|c|}{ Radiotherapy to the affected bone } \\
\hline No & 139 & 62 & I & & I & \\
\hline Yes & 73 & 18 & $0.495(0.293-0.837)$ & 0.009 & $0.452(0.261-0.783)$ & 0.005 \\
\hline \multicolumn{7}{|l|}{ NLR } \\
\hline$<2.48$ & 90 & 21 & & & 1 & \\
\hline$\geq 2.48$ & 122 & 59 & $2.732(1.658-4.503)$ & $<0.0001$ & $2.044(1.211-3.451)$ & 0.007 \\
\hline \multicolumn{7}{|l|}{ LMR } \\
\hline$<3.43$ & 120 & 36 & I & & I & \\
\hline$\geq 3.43$ & 92 & 44 & $0.38 I(0.238-0.609)$ & $<0.0001$ & $0.532(0.324-0.872)$ & 0.012 \\
\hline \multicolumn{7}{|l|}{ CAR } \\
\hline$<0.34$ & 168 & 56 & 1 & & I & \\
\hline$\geq 0.34$ & 44 & 24 & $1.730(1.07 \mid-2.793)$ & 0.025 & $1.340(0.817-2.198)$ & 0.246 \\
\hline
\end{tabular}

Note: Bold text: $P$ value $<0.05$.

Abbreviations: OS, overall survival; HER2, human epidermal growth factor receptor 2; HR, hazard ratio; Cl, confidence interval; T, tumor; $\mathrm{N}$, lymph node involvement; NLR, neutrophil-to-lymphocyte ratio; LMR, lymphocyte-to-monocyte ratio; CAR, C-reactive protein/albumin ratio.

\section{Conclusion}

Our study demonstrated that the number of involved sites of bone metastases $>3$ predicted worse PFS, and the radiotherapy to the affected bone and ER $(+)$ were favorable prognostic factors for breast cancer bone metastases. LMR $<3.43$ and $N L R \geq 2.48$ were both significantly and independently associated with worse survival. With the feature of convenience and accessibility, LMR and NLR could be helpful in predicting the outcome of patients of breast cancer skeletal metastasis.

\section{Abbreviations}

NLR, neutrophil-to-lymphocyte ratio; LMR, lymphocyteto-monocyte ratio; CAR, C-reactive protein/albumin ratio; OS, overall survival; PFS, progression-free survival; HR, hazard ratio; $\mathrm{CI}$, confidence interval; ER, estrogen receptor; PR, progesterone receptor; HER2, human epidermal growth factor receptor 2; SREs, skeletal-related events.

\section{Data Sharing Statement}

The underlying de-identified data used and analyzed during the current study are available from the corresponding author upon reasonable request.

\section{Ethics Approval and Consent}

The study complied with the Declaration of Helsinki. All procedures involving human participants in this study approved by the ethics committee of the First Affiliated Hospital of Medical College of Shihezi University. Written forms of informed consent for individual patients were not required since the study was retrospective. All data analyzed is anonymous. Patients or their legal guardians know of and approved the publication.

\section{Acknowledgments}

We thank all of the clinical investigators and involved patients in this study.

\section{Disclosure}

The authors report no conflicts of interest in this work.

\section{References}

1. Siegel RL, Miller KD, Jemal A. Cancer statistics, 2019. CA Cancer J Clin. 2019;69(1):7-34. doi:10.3322/caac.21551

2. Li BT, Wong MH, Pavlakis N. Treatment and prevention of bone metastases from breast cancer: a comprehensive review of evidence for clinical practice. J Clin Med. 2014;3(1):1-24. doi:10.3390/ jcm3010001 
3. Mundy GR. Metastasis to bone: causes, consequences and therapeutic opportunities. Nat Rev Cancer. 2002;2(8):584-593. doi:10.1038/ nrc867

4. Balkwill F, Mantovani A. Cancer and inflammation: implications for pharmacology and therapeutics. Clin Pharmacol Ther. 2010;87 (4):401-406. doi:10.1038/clpt.2009.312

5. Hanahan D, Weinberg RA. Hallmarks of cancer: the next generation. Cell. 2011;144(5):646-674. doi:10.1016/j.cell.2011.02.013

6. Duan J, Pan L, Yang M. Preoperative elevated neutrophil-to-lymphocyte ratio (NLR) and derived NLR are associated with poor prognosis in patients with breast cancer: a meta-analysis. Medicine (Baltimore). 2018;97(49):e13340. doi:10.1097/MD.0000000000013340

7. Mandaliya H, Jones M, Oldmeadow C, et al. Prognostic biomarkers in stage IV non-small cell lung cancer (NSCLC): neutrophil to lymphocyte ratio (NLR), lymphocyte to monocyte ratio (LMR), platelet to lymphocyte ratio (PLR) and advanced lung cancer inflammation index (ALI). Transl Lung Cancer Res. 2019;8(6):886-894. doi:10.21037/tlcr.2019.11.16

8. Liu Z, Shi H, Chen L. Prognostic role of pre-treatment C-reactive protein/albumin ratio in esophageal cancer: a meta-analysis. $B M C$ Cancer. 2019;19(1):1161. doi:10.1186/s12885-019-6373-y

9. Thio QCBS, Goudriaan WA, Janssen SJ, et al. Prognostic role of neutrophil-to-lymphocyte ratio and platelet-to-lymphocyte ratio in patients with bone metastases. Br J Cancer. 2018;119(6):737-743. doi:10.1038/s41416-018-0231-6

10. Network National Comprehensive Cancer. NCCN clinical practice guidelines in oncology. Breast Cancer. V.1.2016.[2016-09-13]. Available from: http://www.nccn.org/professionals/physician_gls/ pdf/breast.pdf. Accessed October 15, 2020.

11. Tahara RK, Brewer TM, Theriault RL, et al. Bone metastasis of breast cancer. Adv Exp Med Biol. 2019;1152:105-129. doi:10.1007/ 978-3-030-20301-6_7

12. Tao Z, Shi A, Lu C, et al. Breast cancer: epidemiology and etiology. Cell Biochem Biophys. 2015;72(2):333-338. doi:10.1007/s12013-014-0459-6

13. Karki R, Man SM, Kanneganti T-D. Inflammasomes and cancer. Cancer Immunol Res. 2017;5(2):94-99. doi:10.1158/2326-6066. CIR-16-0269

14. Miyamoto R, Inagawa S, Sano N, et al. The neutrophil-tolymphocyte ratio (NLR) predicts short-term and long-term outcomes in gastric cancer patients. Eur J Surg Oncol. 2018;44(5):607-612. doi:10.1016/j.ejso.2018.02.003

15. Goto W, Kashiwagi S, Asano Y, et al. Predictive value of lymphocyte-to-monocyte ratio in the preoperative setting for progression of patients with breast cancer. BMC Cancer. 2018;18(1):1137. doi:10.1186/s12885-018-5051-9

16. Zhou W, Zhang G-L, Hutson AD. C-reactive protein to albumin ratio predicts the outcome in renal cell carcinoma: a meta-analysis. PLoS One. 2019;14(10):e0224266. doi:10.1371/journal.pone.0224266

17. Dolan RD, McSorley ST, Park JH, et al. The prognostic value of systemic inflammation in patients undergoing surgery for colon cancer: comparison of composite ratios and cumulative scores. $\mathrm{Br}$ $J$ Cancer. 2018;119(1):40-51. doi:10.1038/s41416-018-0095-9

18. Ownby HE, Roi LD, Isenberg RR, et al. Peripheral lymphocyte and eosinophil counts as indicators of prognosis in primary breast cancer. Cancer. 2006;52(1):126-130. doi:10.1002/1097-0142(19830701) 52:1<126::aid-cncr2820520123>3.0.co;2-y

Cancer Management and Research

Publish your work in this journal

Cancer Management and Research is an international, peer-reviewed open access journal focusing on cancer research and the optimal use of preventative and integrated treatment interventions to achieve improved outcomes, enhanced survival and quality of life for the cancer patient.
19. Fridman WH, Pagès F, Sautès-Fridman C, et al. The immune contexture in human tumours: impact on clinical outcome. Nat Rev Cancer. 2012;12(4):298-306. doi:10.1038/nrc3245

20. Hiraoka N. Tumor-infiltrating lymphocytes and hepatocellular carcinoma: molecular biology. Int J Clin Oncol. 2010;15(6):544-551. doi:10.1007/s10147-010-0130-1

21. Kang M, Jeong CW, Kwak C, et al. Preoperative neutrophil-lymphocyte ratio can significantly predict mortality outcomes in patients with non-muscle invasive bladder cancer undergoing transurethral resection of bladder tumor. Oncotarget. 2017;8(8):12891-12901. doi:10.18632/ oncotarget.14179

22. Peng L-S, Zhang J-Y, Teng Y-S, et al. Tumor-associated monocytes/ macrophages impair NK-cell function via TGF $\beta 1$ in human gastric cancer. Cancer Immunol Res. 2017;5(3):248-256. doi:10.1158/23266066.CIR-16-0152

23. Ribatti D, Vacca A. The role of inflammatory cells in angiogenesis in multiple myeloma. Adv Exp Med Biol. 2014;816:361-376. doi:10.1007/978-3-0348-0837-8_14

24. Wilcox RA, Wada DA, Ziesmer SC, et al. Monocytes promote tumor cell survival in T-cell lymphoproliferative disorders and are impaired in their ability to differentiate into mature dendritic cells. Blood. 2009;114(14):2936-2944. doi:10.1182/blood-2009-05-220111

25. Zhan H, Ma J-Y, Jian Q-C. Prognostic significance of pretreatment neutrophil-to-lymphocyte ratio in melanoma patients: a meta-analysis. Clin Chim Acta. 2018;484:136-140. doi:10.1016/j. cca.2018.05.055

26. Di Carlo E, Forni G, Lollini P, et al. The intriguing role of polymorphonuclear neutrophils in antitumor reactions. Blood. 2001;97 (2):339-345. doi:10.1182/blood.v97.2.339

27. Smith JA. Neutrophils, host defense, and inflammation: a double-edged sword. J Leukoc Biol. 1994;56(6):672-686. doi: $10.1002 / \mathrm{jlb} .56 .6 .672$

28. Wang S, Zhang Z, Fang F, et al. The neutrophil/lymphocyte ratio is an independent prognostic indicator in patients with bone metastasis. Oncol Lett. 2011;2(4):735-740. doi:10.3892/ol.2011.304

29. Jiang ZF, Song EW, Wu H, et al. Guidelines for the diagnosis and treatment of breast cancer by the Chinese society of clinical oncology (2019 edition). Chin J Cancer. 2019;29(08):609-680. doi:10.19401/j. cnki.1007-3639.2019.08.009

30. Parkes A, Warneke CL, Clifton K, et al. Prognostic factors in patients with metastatic breast cancer with bone-only metastases. Oncologist. 2018;23(11):1282-1288. doi:10.1634/theoncologist.2018-0085

31. Lumachi F, Brunello A, Maruzzo M, et al. Treatment of estrogen receptor-positive breast cancer. Curr Med Chem. 2013;20 (5):596-604. doi:10.2174/092986713804999303

32. Lim E, Metzger-Filho O, Winer EP. The natural history of hormone receptor-positive breast cancer. Oncology (Williston Park). 2012;26 (8):688-696.

33. Band V, Mirza S, Mohibi S, et al. Mouse models of estrogen receptor-positive breast cancer. $J$ Carcinog. 2011;10(1):35. doi:10.4103/1477-3163.91116

34. Ren Z, Li Y, Hameed O, et al. Prognostic factors in patients with metastatic breast cancer at the time of diagnosis. Pathol Res Pract. 2014;210(5):301-306. doi:10.1016/j.prp.2014.01.008
The manuscript management system is completely online and includes a very quick and fair peer-review system, which is all easy to use. Visit http://www.dovepress.com/testimonials.php to read real quotes from published authors. 